\title{
Large Cecal Lipoma With Overlying Ulceration Simulating Malignancy: A Case Report and Review of Relevant Literature
}

\author{
Saptarshi Biswas ${ }^{\mathrm{a}, \mathrm{e}}$, Arpit Amin ${ }^{\mathrm{b}}$, Eddy A Castillo ${ }^{\mathrm{c}}$, Anthy Demestihas ${ }^{\mathrm{d}}$
}

\begin{abstract}
Gastrointestinal lipomas are rare, usually single, slow growing benign non-epithelial tumors. Most colonic lipomas are asymptomatic and are usually detected incidentally during colonoscopy, surgery or autopsy. In a small percentage of cases, especially when their diameter is greater than $2 \mathrm{~cm}$, they can cause symptoms. The common presenting symptoms include constipation, diarrhea, colicky abdominal pain, change in bowel habit, bowel obstruction, lower gastrointestinal bleeding, intussusception or prolapse. Imaging techniques, including CT and MRI are regularly used. However, preoperative diagnosis of colonic lipoma is often difficult with the majority of the lesions diagnosed by laparotomy and definitive diagnosis is made based on histopathological examination. Colonoscopy permits direct visualization of the submucosal lipoma. Endoscopy can usually distinguish lipomas from other tumors. Lipomas are seen as smooth, rounded yellowish polyps with a thick stalk or broad-based attachment. Typical colonoscopy features are the "tent sign" (elevation of the mucosa over lipoma with biopsy forceps), "cushion sign" or "pillow sign" (pressing forceps against the lesion results in depression or pillowing of the mass) and the "naked fat sign" (extrusion of yellowish fat at the biopsy site. The mucosa overlying a colonic lipoma is intact. In rare cases, colonoscopy may reveal large-sized flat-shaped mass with ulceration that may lead to an impression of malignancy. Colonoscopic biopsy is often performed to determine the exact nature of the tumor. However colonic
\end{abstract}

Manuscript accepted for publication April 19, 2012 lipomas may result in mucosal inflammation of adjacent tissue giving the false impression of "nonspecific colitis". This is particularly true in cases of inadequate tissue sample. Recently, virtual colonoscopy has been performed to detect colonic lipomas. Lipomas less than $2 \mathrm{~cm}$ in diameter can be removed endoscopically whereas larger lesions should be removed surgically either by open or laparoscopic methods. Colonoscopic resection of large colonic lipomas remains a controversial subject till date. Although a wide range of operative techniques including colostomy and excision, hemicolectomy or subtotal colectomy are employed, segmental resection is usually the procedure of choice. We describe a patient with persistent abdominal pain who underwent open right hemicolectomy for the presumptive endoscopic diagnosis of cecal adenocarcinoma and discuss diagnostic modalities and treatment options. Histological examination confirmed that the resected specimen was a giant benign cecal lipoma.

Keywords: Giant; Cecal Lipoma; Malignancy simulation

\section{Introduction}

Gastrointestinal lipomas are rare, usually single, slow growing benign non-epithelial tumors. Although they can be found in the esophagus, small intestine and rarely in the stomach, colonic lipomas constitute the most common mesenchymal neoplasm of the gastrointestinal tract [1-3].

Most colonic lipomas are asymptomatic and are usually

${ }^{a}$ Department of General Surgery and Surgical Critical Care, Westchester University Medical Center, NYMC, Valhalla, NY, USA

${ }^{\mathrm{b}}$ Department of General Surgery, Westchester University Medical Center, NYMC, Valhalla, NY, USA

${ }^{\mathrm{c}}$ Department of Gastrointestinal Medicine, St Vincents Medical Center, Bridgeport, CT, USA

${ }^{\mathrm{d} D e p a r t m e n t ~ o f ~ G e n e r a l ~ S u r g e r y, ~ S t ~ V i n c e n t s ~ M e d i c a l ~ C e n t e r, ~ B r i d g e p o r t, ~}$ CT, USA

${ }^{\mathrm{e}}$ Corresponding author: Saptarshi Biswas, Department of General Surgery and Surgical Critical Care, Westchester University Medical Center, NYMC, Valhalla, NY, USA.

Email: saptarshibiswas@comcast.net

doi: http://dx.doi.org/10.4021/jcs34w



Figure 1. Distal esophagitis 


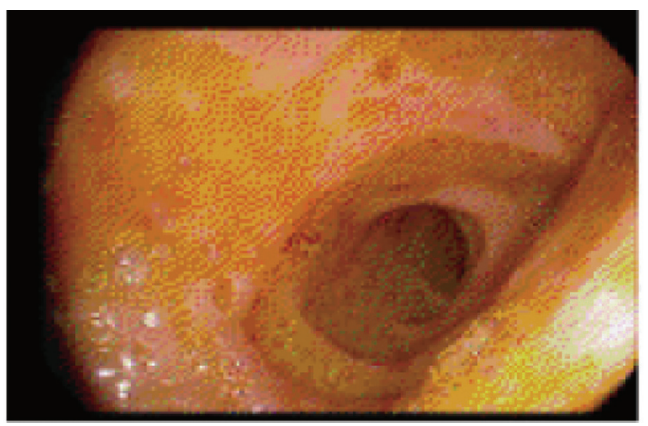

Figure 2. Bulb Duodenitis

detected incidentally during colonoscopy, surgery or autopsy. In a small percentage of cases, especially when their diameter is greater than $2 \mathrm{~cm}$, they can cause symptoms. The common presenting symptoms include constipation, diarrhea, colicky abdominal pain, change in bowel habit, bowel obstruction, lower gastrointestinal bleeding, intussusception or prolapse $[1,3,4]$.

Imaging techniques, including $\mathrm{CT}$ and MRI are regularly used. However, preoperative diagnosis of colonic lipoma is often difficult with the majority of the lesions diagnosed by laparotomy and definitive diagnosis is made based on histopathological examination [2].

The usual colonoscopic picture consists of a smooth, spherical polyp, usually sessile (rarely penduculated) slightly yellow in color, while the overlying mucosa is intact [1-4]. In rare cases, the mucosa consists of necrotic and/or ulcerative lesions, which resemble malignant tumors as in this present case [4].

Lipomas less than $2 \mathrm{~cm}$ in diameter can be removed endoscopically whereas larger lesions should be removed surgically either by open or laparoscopic methods. Colonoscopic resection of large colonic lipomas remains a controversial subject till date $[1,2,4]$. Although a wide range of operative techniques including colostomy and excision, hemicolectomy or subtotal colectomy are employed, segmental resection

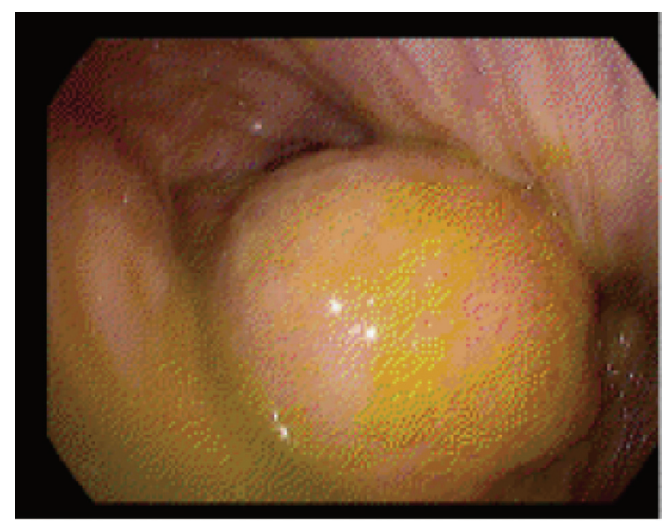

Figure 3. Cecal mass

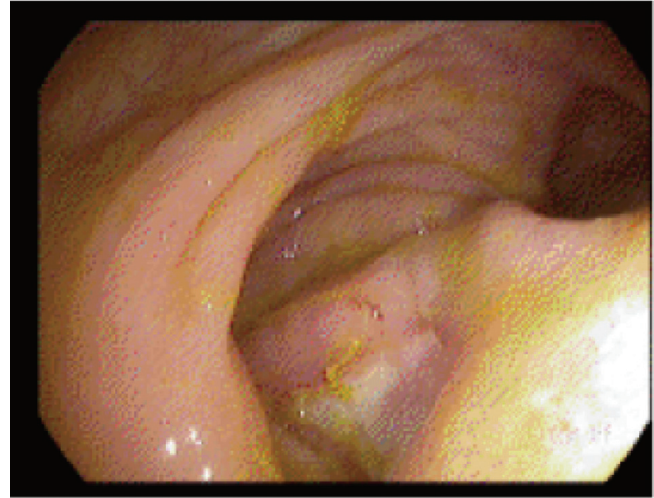

Figure 4. Ulcerated base of cecal mass

is usually the procedure of choice [2].

We describe a patient with persistent abdominal pain who underwent open right hemicolectomy for the presumptive endoscopic diagnosis of cecal adenocarcinoma and discuss diagnostic modalities and treatment options. Histological examination confirmed that the resected specimen was a benign cecal lipoma.

\section{Case Report}

A 54-year-old Hispanic male presented as an outpatient with two month history of daily postprandial nausea, vomiting, diffuse abdominal pain and constipation. The patient reported weight loss of $15 \mathrm{lbs}$ in the preceding four months. The patient denied any history of hematemesis, dysphagia, odynophagia, melena, bright red blood per rectum, or jaundice. His past medical history was significant for rectal abscess, which resolved with incision and drainage 14 years ago. The patient was not taking any medications at home. The patient was not allergic to any medications. There was no history of cancer in his family. The patient's father suffered from peptic ulcer disease. His social history was significant for 1 pack per day cigarette smoking for the past 44 years.

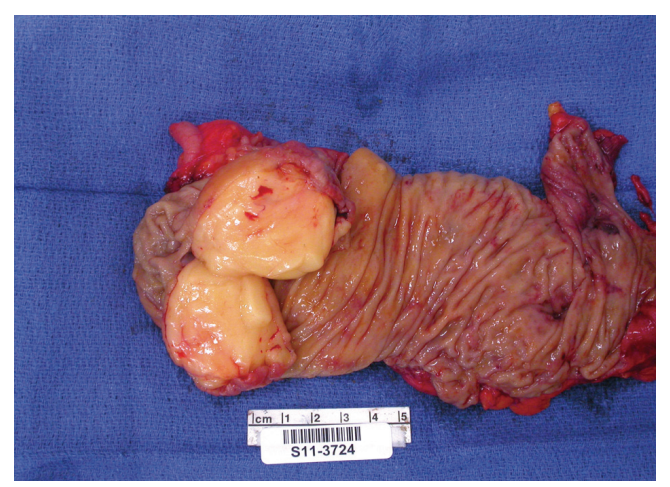

Figure 5. Cecal lipoma (gross view) 


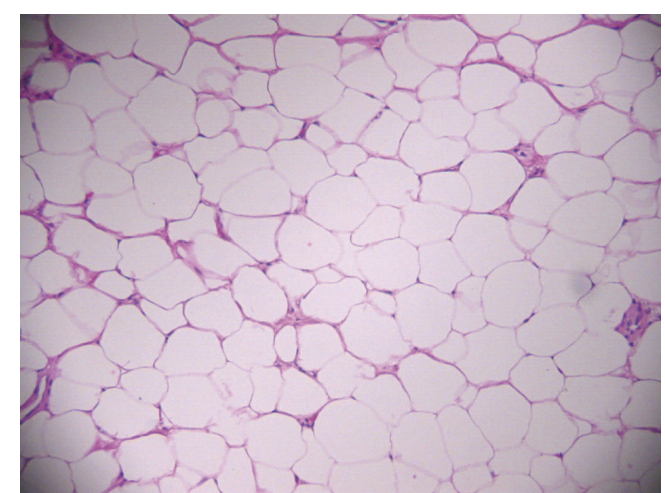

Figure 6. Cecal lipoma (microscopic view)

On physical examination, his vital signs were stable. Head and neck examination was negative for icterus. Abdominal examination revealed normoactive bowel sounds, non-distended abdomen, and mild diffuse tenderness to palpation. Initial laboratory tests including complete blood count and comprehensive metabolic panel were normal. Abdominal ultrasound examination did not demonstrate any biliary pathology.

Upper endoscopy revealed esophagitis (Fig. 1) and duodenitis (Fig. 2). Biopsies were obtained, which were negative for dysplasia. The patient was started on proton pump inhibitor. The patient's symptoms persisted despite treatment with proton pump inhibitor. Colonoscopy revealed small internal hemorrhoids, $5 \mathrm{~mm}$ sessile polyp in the mid-transverse colon, which was excised, and a large ulcerated cecal mass at the appendiceal orifice with length of $6-7 \mathrm{~cm}$ (Fig. 3, 4). A biopsy of the ulcerated cecal mass was obtained, which was negative for malignancy. CT scan of abdomen and pelvis with $\mathrm{PO}$ and IV contrast was obtained, which revealed a $4.5 \mathrm{~cm} \times 4.2 \mathrm{~cm} \times 4.6 \mathrm{~cm}$ cecal mass with $\mathrm{HU}$ of -114 , which was consistent with density of fat. There was no bowel obstruction present.

Patient was referred to surgery for possible right hemicolectomy due to persistent symptoms despite medical therapy. Intra-operatively, a palpable intraluminal cecal mass was found, which was concordant with the location found on colonoscopy. Right hemicolectomy was performed. Pathologic evaluation of the right hemicolectomy specimen revealed $6.0 \mathrm{~cm}$ cecal lipoma showing ulceration and hyperplasia of surface mucosal glands (Fig. 5, 6). The patient's pain resolved after surgery and he was discharged home on regular diet on post-operative day 4.

\section{Discussion}

\section{Incidence}

Colonic lipomas are mesenchymal in origin and arising from adipose tissue in the bowel wall [2, 5-7]. In the gastrointestinal tract, at least $70 \%$ of lipomas are located on the right side of the colon. In the descending order of prevalence, other colonic locations are the transverse colon, including both hepatic and splenic flexures, descending colon, sigmoid colon and rectum [2, 5-10]. Gastrointestinal lipomas are also reported in the small intestine $(25 \%)$ stomach $(5 \%)$ and esophagus [6, 11-13].

Colonic lipoma was first described by Bauer in 1757 [1, 14]. A review by Franc-Law et al revealed that there were only 275 cases of colonic lipomas reported in English literature until 2001 [15]. Large bowel lipomas are rare adipose neoplasms with a reported incidence ranging between $0.15-4.4 \%[2,16]$. A review of 1310 autopsies by Weinberg and Feldman revealed an incidence of 4.4\% [17]. However, a meta-analysis performed by the same authors showed that the incidence of colonic lipomas is only $0.2 \%$ [17].

Most colonic lipomas are solitary [2]. However, in 10 to $25 \%$ of cases, they can be multiple [4]. Colonic lipomatosis, which is a rare lipomatosis syndrome, is characterized by the presence of numerous lipomas throughout the large bowel $[4,18]$.

The affected population is mostly elderly with a peak incidence in the fifth to sixth decade of life with a female predominance $[2,16,19-21]$.

\section{Presentations}

Colonic lipomas usually do not cause symptoms and are usually discovered incidentally at colonoscopy, surgery or autopsy. Less than one-fourth of patients with colonic lipoma present with symptoms [4]. Taylor BA et al from Mayo clinic reported that only $6 \%$ of colonic lipomas were symptomatic $[2,22]$. If the lipoma diameter is larger than $2 \mathrm{~cm}$, they may cause symptoms like abdominal pain, diarrhea, constipation, weight loss, anemia, gastrointestinal bleeding or bowel obstruction [1].

These symptoms occur due to intussuseption, direct luminal protrusion of the enlarging mass or ulceration of the surrounding mucosa. Acute or intermittent colo-colonic or ileo-colonic intussusception leads to mechanical interference causing symptoms in large colonic lipomas [2, 21, 22]. Although rare, lipoma is the most common benign tumor of the colon which causes colonic intussusception in adults [23]. On rare occasions, ulceration of the overlying mucosa may cause clinically apparent lower gastrointestinal bleeding or result in chronic anemia [24-27]. There have been case reports describing spontaneous expulsion of sigmoid lipomas $[2,20]$.

\section{Etiology}

The true etiology of gastrointestinal lipomas is still not clearly understood $[28,29]$. Colonic lipomas originate from 
the sub mucosa and protrude into the gastrointestinal lumen. They rarely extend into the muscularis propria or subserosa. They have a polypoid appearance and a well-circumscribed margin.

At times, the lipoma may be a result of chronic inflammation. This is especially true in the cecum. The chronic inflammatory process may cause abnormal intestinal motility and the mucosa to pull away from the deeper submucosa, resulting in the creation of a tissue space with subsequent adipose tissue deposition. The deposited adipose tissues have no well-defined margins with adjacent tissues, and the overlying and adjacent colonic mucosa always presents with inflammatory changes making preoperative diagnosis increasingly difficult. Some authors have addressed them as, "pseudolipoma". The differentiation of true neoplastic lipoma and pseudolipoma is still not well recognized.

\section{Radiological diagnosis}

Numerous imaging modalities are used in the diagnosis of colonic lipomas. However, colonic lipomas continue to present difficulties in the preoperative differentiation between malignant and benign colonic neoplasm.

Barium enema can detect lipomas but they are not specific. An ovoid filling defect with well-defined borders found on barium enema may raise the suspicion for the diagnosis of colonic lipoma. A change in size and shape of a radiolucent lesion in response to peristalsis or the application of external pressure to the abdomen can sometimes be elicited. This is known as the "squeeze sign" $[4,30]$. They can however be more informative in cases of colonic lipomas causing intussusceptions [25].

CT scan may demonstrate a well-circumscribed intraluminal mass with absorption densities characteristic of fatty tissue (-40 to -120 Hounsfield units) [3, 31-34]. At times, CT scans are not informative. This may be attributed to a large ulcerated mass with a broad base, ill-defined borders, and granulation tissue formation, which are different from the typical polypoid mass containing fatty tissue and protruding into the lumen.

Signal intensities characteristic of fatty tissue on T1weighted and fat-suppressing images on magnetic resonance imaging (MRI) may be useful in the detection of lipomas [3]. However, further investigation is necessary before this modality is used to confirm the diagnosis of lipomas [35-37].

Endoscopic ultrasonography (EUS) is a very effective modality for characterizing submucosal tumors because it identifies the layer of origin of the submucosal lesion. The five-layer structure of the colorectal wall seen on endoscopic ultrasonography corresponds to the histologic appearance [29]. Colonic lipomas appear as hyperechoic homogeneous masses arising from the third layer on endoscopic ultrasonography $[30,31]$. This characteristic appearance can be used to differentiate lipomas from lymphangioma, smooth muscle tumors, and metastatic malignancies [29]. EUS can also be used as a tool to determine any extension into the muscularis propria before injection-assisted polypectomy of symptomatic lipomas [30].

Colonoscopy permits direct visualization of the submucosal lipoma. Endoscopy can usually distinguish lipomas from other tumors. Lipomas are seen as smooth, rounded yellowish polyps with a thick stalk or broad-based attachment. Typical colonoscopy features are the "tent sign" (elevation of the mucosa over lipoma with biopsy forceps), "cushion sign" or "pillow sign" (pressing forceps against the lesion results in depression or pillowing of the mass) and the "naked fat sign" (extrusion of yellowish fat at the biopsy site [32-37]. The mucosa overlying a colonic lipoma is intact.

In rare cases, colonoscopy may reveal large-sized flatshaped mass with ulceration that may lead to an impression of malignancy [25]. Colonoscopic biopsy is often performed to determine the exact nature of the tumor. However colonic lipomas may result in mucosal inflammation of adjacent tissue giving the false impression of "nonspecific colitis". This is particularly true in cases of inadequate tissue sample [11]. Recently, virtual colonoscopy has been performed to detect colonic lipomas [27].

\section{Treatment options}

The treatment of colonic lipomas depends on the preoperative diagnosis combined with the intraoperative findings on the frozen section. Various treatment options include local excision, segmental resection, or formal hemicolectomy. If the intraoperative frozen section reveals malignant disease, resection of the involved segment along with the regional nodal basin is recommended. On the other hand, if the intraoperative frozen pathology reveals benign pathology, simple resection is performed. In short, intraoperative pathology is the most important factor determining the treatment approach for colonic lipomas $[35,38]$. If the colonic lipoma is asymptomatic, less than $2 \mathrm{~cm}$ in diameter and colonoscopic biopsy reveals benign pathology, it can be observed. Malignant transformation of such colonic lipomas is extremely rare [39]. If the colonic lipoma presents as intussusception, a primary adenocarcinoma should be suspected because $75 \%$ of colonic intussusceptions occur in the setting of a primary adenocarcinoma [35]. Paskauskas et al report that colonic lipomas, especially those causing intussusception, range from 4 to $16 \mathrm{~cm}$ in greatest diameter with an average of $7 \mathrm{~cm} \mathrm{[35].}$ Therefore, size of the colonic lipoma is an important determinant as far as intussusception is concerned.

\section{Endoscopic snaring versus surgical excision}

If the colonic lipoma is symptomatic, less than $2 \mathrm{~cm}$ in diameter, and is pedunculated, it can be removed safely using endoclipping or endoloop ligation [40-42]. If the colonic 
lipoma is symptomatic, larger than $2 \mathrm{~cm}$ in diameter, and is sessile or broad based, endoscopic approach is associated with a greater risk of perforation. Hence, surgical removal is recommended for such lesions [23, 43].

Laparoscopic colon surgery involves less pain in the post operative period, shorter hospital stay and a faster recovery than conventional formal laparotomy. A number of recent published data referring to the comparison of laparoscopic versus open colorectal resection for cancer indicate the benefit of laparoscopic resection of colonic lipomas and underline the fact that they should become the gold standard method for removal of lipomas especially when they are greater than $2 \mathrm{~cm}$ in diameter, even in cases where the malignancy of the tumor could not be excluded preoperatively $[44,45]$.

Jiang et al suggest that the surgical removal should be the preferred choice for the following indications [38]: 1) Lipoma with a diameter of greater than $4 \mathrm{~cm}$, with a sessile appearance or limited pedicle; 2) Lipoma with an unclear preoperative diagnosis; 3) Lesions with significant symptoms, especially the appearance of intussusceptions; 4) Lesions with involvement of the muscular layer or serosa; 5) Lesions that cannot be resected radically by colonoscopy.

However, based on our case and the published literature, we think that surgical removal should be the preferred choice for colonic lipomas if the tumors are symptomatic and larger than $2 \mathrm{~cm}$ in diameter.

\section{Conclusion}

Colonic lipomas are rare nonepithelial benign tumors. Accurate preoperative diagnosis is often difficult and as a result they can be mistaken for malignancy. This is more so when the lesion is large in size, and with ulceration. Pedunculated colonic lipomas of small dimensions can be safely removed endoscopically. Surgical resection is recommended for larger lipomas to relieve the symptoms or exclude malignancy. A segmental resection, hemicolectomy or subtotal colectomy may be necessary in cases when diagnosis is questionable or when a complication occurs. A surgical approach either open or laparoscopic remains the treatment of choice for large and complicated cases.

\section{References}

1. El Tinay OY, Khan IA, Noureldin OH, Al Boukai AA. Caecal lipoma causing colo-colonic intussusception. Saudi J Gastroenterol. 2003;9(3):145-147.

2. Ghidirim G, Mishin I, Gutsu E, Gagauz I, Danch A, Russu S. Giant submucosal lipoma of the cecum: report of a case and review of literature. Rom J Gastroenterol. 2005;14(4):393-396.

3. Katsinelos P, Chatzimavroudis G, Zavos C, Pilpilidis I, Lazaraki G, Papaziogas B, Paroutoglou G, et al. Ce- cal lipoma with pseudomalignant features: a case report and review of the literature. World J Gastroenterol. 2007;13(17):2510-2513.

4. Mandana S, Kawatra V, Dhingra K, Gupta P, Khurana N. Lipomatous polyp presenting with intestinal intussusception in adults: A report of four cases. Gastroenterol Res 2010; 3 (5): 229-231.

5. Aytac B, Yerci O, Gurel S, Ferik Z. Colonic lipomas mimicking colon cancer. Turk Patholoji Dergisi 2010; 26 (3): 196-199.

6. Huh KC, Lee TH, Kim SM, Im EH, Choi YW, Kim BK, Jung DJ, et al. Intussuscepted sigmoid colonic lipoma mimicking carcinoma. Dig Dis Sci. 2006;51(4):791-795.

7. Adachi S, Hamano R, Shibata K, Yoshida S, Tateishi H, Kobayashi T, Hanada M. Colonic lipoma with florid vascular proliferation and nodule-aggregating appearance related to repeated intussusception. Pathol Int. 2005;55(3):160-164.

8. Gurses B, Kabakci N, Akyuz U, Pata C, Taviloglu K, Kovanlikaya I. Imaging features of a cecal lipoma as a lead point for colo-colonic intussusception. Emerg Radiol. 2008;15(2):133-136.

9. Kabaalioglu A, Gelen T, Aktan S, Kesici A, Bircan O, Luleci E. Acute colonic obstruction caused by intussusception and extrusion of a sigmoid lipoma through the anus after barium enema. Abdom Imaging. 1997;22(4):389391.

10. Rogers SO, Jr., Lee MC, Ashley SW. Giant colonic lipoma as lead point for intermittent colo-colonic intussusception. Surgery. 2002;131(6):687-688.

11. Zhang H, Cong JC, Chen CS, Qiao L, Liu EQ. Submucous colon lipoma: a case report and review of the literature. World J Gastroenterol. 2005;11(20):3167-3169.

12. Zografos G, Tsekouras DK, Lagoudianakis EE, Karantzikos G. Small intestinal lipoma as a cause of massive gastrointestinal bleeding identified by intraoperative enteroscopy. A case report and review of the literature. Dig Dis Sci. 2005;50(12):2251-2254.

13. Santhanam AN, Sillar RW, Roberts-Thomson IC. Education and imaging. Gastrointestinal: gastrointestinal lipomas. J Gastroenterol Hepatol. 2006;21(10):1628.

14. Haller JD, Roberts TW. Lipomas of the Colon: A Clinicopathologic Study of 20 Cases. Surgery. 1964;55(773781.

15. Chung YF, Ho YH, Nyam DC, Leong AF, Seow-Choen F. Management of colonic lipomas. Aust N Z J Surg. 1998;68(2):133-135.

16. Weinberg T, Feldman M, Sr. Lipomas of the gastrointestinal tract. Am J Clin Pathol. 1955;25(3):272-281.

17. Franc-Law JM, Begin LR, Vasilevsky CA, Gordon PH. The dramatic presentation of colonic lipomata: report of two cases and review of the literature. Am Surg. 2001;67(5):491-494.

18. Tatsuguchi A, Fukuda Y, Moriyama T, Yamanaka N. 
Lipomatosis of the small intestine and colon associated with intussusception in the ileocecal region. Gastrointest Endosc. 1999;49(1):118-121.

19. Rogy MA, Mirza D, Berlakovich G, Winkelbauer F, Rauhs R. Submucous large-bowel lipomas--presentation and management. An 18-year study. Eur J Surg. 1991;157(1):51-55.

20. Ryan J, Martin JE, Pollock DJ. Fatty tumours of the large intestine: a clinicopathological review of 13 cases. Br J Surg. 1989;76(8):793-796.

21. Michowitz M, Lazebnik N, Noy S, Lazebnik R. Lipoma of the colon. A report of 22 cases. Am Surg. 1985;51(8):449-454.

22. Taylor BA, Wolff BG. Colonic lipomas. Report of two unusual cases and review of the Mayo Clinic experience, 1976-1985. Dis Colon Rectum. 1987;30(11):888-893.

23. Raju GS, Gomez G. Endoloop ligation of a large colonic lipoma: a novel technique. Gastrointest Endosc. 2005;62(6):988-990.

24. El-Khalil T, Mourad FH, Uthman S. Sigmoid lipoma mimicking carcinoma: case report with review of diagnosis and management. Gastrointest Endosc. 2000;51(4 Pt 1):495-496.

25. Meghoo CA, Cook PR, McDonough CA, Bowser LK, Waddell BE. Large colonic lipoma with mucosal ulceration mimicking carcinoma. Gastrointest Endosc. 2003;58(3):468-470.

26. Vasiliadis K, Katsamakas M, Nikolaidou A, Christoforidis $\mathrm{E}$, Tsalis $\mathrm{K}$, Tsalikidis A. Submucosal lipoma of the ascending colon as a source of massive lower gastro-intestinal bleeding: a case report. Acta Chir Belg. 2008;108(3):356-359.

27. de Ruijter SH, van Marle AG, Doornewaard H, Melse JC. [Submucosal lipoma of the colon: abdominal cramps with rectal bleeding and weight loss]. Ned Tijdschr Geneeskd. 2006;150(36):1990-1993.

28. Zhang X, Ouyang J, Kim YD. Large ulcerated cecal lipoma mimicking malignancy. World J Gastrointest Oncol. 2010;2(7):304-306.

29. Worthen WF, 2nd, Worthen N, State D, Hirose FM. Lipoma of the cecum clinically simulating carcinoma. Dis Colon Rectum. 1979;22(4):270-273.

30. Kaplan P. Submucous lipoma of the colon. Report of a case. Int Surg. 1971;56(2):113-117.

31. Buetow PC, Buck JL, Carr NJ, Pantongrag-Brown L, Ros PR, Cruess DF. Intussuscepted colonic lipomas: loss of fat attenuation on CT with pathologic correlation in 10 cases. Abdom Imaging. 1996;21(2):153-156.
32. Kakitsubata Y, Kakitsubata S, Nagatomo H, Mitsuo H, Yamada H, Watanabe K. CT manifestations of lipomas of the small intestine and colon. Clin Imaging. 1993;17(3):179-182.

33. Wulff C, Jespersen N. Colo-colonic intussusception caused by lipoma. Case reports. Acta Radiol. 1995;36(5):478-480.

34. Heiken JP, Forde KA, Gold RP. Computed tomography as a definitive method for diagnosing gastrointestinal lipomas. Radiology. 1982;142(2):409-414.

35. Paskauskas S, Latkauskas T, Valeikaite G, Parseliunas A, Svagzdys S, Saladzinskas Z, Tamelis A, et al. Colonic intussusception caused by colonic lipoma: a case report. Medicina (Kaunas). 2010;46(7):477-481.

36. Younathan CM, Ros PR, Burton SS. MR imaging of colonic lipoma. J Comput Assist Tomogr. 1991;15(3):492494.

37. Liessi G, Pavanello M, Cesari S, Dell'Antonio C, Avventi P. Large lipomas of the colon: CT and MR findings in three symptomatic cases. Abdom Imaging. 1996;21(2):150-152.

38. Jiang L, Jiang LS, Li FY, Ye H, Li N, Cheng NS, Zhou Y. Giant submucosal lipoma located in the descending colon: a case report and review of the literature. World J Gastroenterol. 2007;13(42):5664-5667.

39. Aytac B, Yerci O, Gurel S, Ferik Zarema. Colonic lipomas mimicking colon cancer. Turkish Journal of Pathology 2010; 26 (3): 196-199.

40. Katsinelos P, Chatzimavroudis G, Zavos C, Paroutoglou G, Papaziogas B, Kountouras J. A novel technique for the treatment of a symptomatic giant colonic lipoma. J Laparoendosc Adv Surg Tech A. 2007;17(4):467-469.

41. Creasy TS, Baker AR, Talbot IC, Veitch PS. Symptomatic submucosal lipoma of the large bowel. Br J Surg. 1987;74(11):984-986.

42. Bar-Meir S, Halla A, Baratz M. Endoscopic removal of colonic lipoma. Endoscopy. 1981;13(3):135-136.

43. Pfeil SA, Weaver MG, Abdul-Karim FW, Yang P. Colonic lipomas: outcome of endoscopic removal. Gastrointest Endosc. 1990;36(5):435-438.

44. Zerey M, Burns JM, Kercher KW, Kuwada TS, Heniford BT. Minimally invasive management of colon cancer. Surg Innov. 2006;13(1):5-15.

45. Lezoche E, Guerrieri M, De Sanctis A, Campagnacci R, Baldarelli M, Lezoche G, Paganini AM. Long-term results of laparoscopic versus open colorectal resections for cancer in 235 patients with a minimum follow-up of 5 years. Surg Endosc. 2006;20(4):546-553. 